\title{
Validating the demand for goat meat in the US meat market
}

\author{
Xuanli Liu $^{1 *}$, Mack Nelson ${ }^{2}$, Erika Styles ${ }^{2}$ \\ ${ }^{1}$ Agricultural Research Station, Fort Valley State University, Fort Valley, USA; *Corresponding Author: liux@fvsu.edu \\ ${ }^{2}$ Department of Economics, Fort Valley State University, Fort Valley, USA
}

Received 8 May 2013; revised 9 June 2013; accepted 10 July 2013

Copyright (C) 2013 Xuanli Liu et al. This is an open access article distributed under the Creative Commons Attribution License, which permits unrestricted use, distribution, and reproduction in any medium, provided the original work is properly cited.

\begin{abstract}
There is a large body of literature in economics examining the US meat market, but few studies have focused on the US goat meat market. This study, as a catch-up effort, provides an estimate of the demand for goat meat and assesses the impact of driving factors in the US goat meat market. The data for this study were collected in 11 southern states and specifically elicit the demand and consumer preferences in this nonconventional market. Four econometric models are fitted to examine the multiple layers of the demand, including the current, the potential, the latent, and the seasonal demand. Findings indicate a substantial demand for goat meat with great growth potential, driven by demographic factors and food safety concerns. Ethnic groups and the aged comprise the current niches for goat meat, and the preferences for healthy and safe meat will define the market in the future.
\end{abstract}

Keywords: Market; Demand; Consumer

Preferences; Ethnics; Goat Meat

\section{INTRODUCTION}

The past decades have witnessed substantial changes in the US meat market. The declining demand for beef, the growing demand for poultry, and the leveling off of demand for pork characterize the well-known consumption shift from red to white meat [1]. Driving the shift is consumers' increasing demand for healthy meat and meat products [2]. In fact, the attributes related to meat safety have become a critical component in motivating consumers to make food selection [3,4]. A study from the USDA ranked health concerns as the number one factor influencing consumer demand for meat products [1], and choice experiment studies confirmed consumers' willing- ness to pay (WTP) for products with a USDA certified organic label [5]. Discussion in a broader spectrum regarding meat markets and consumer preferences could be referenced to many other studies [2,6-9].

A result of interest from the preference shift of consumers is that the US goat meat market has been stimulated, which, for a long time, has been a stagnant niche. It is now recognized by researchers and consumers that there is a good match between goat meat and their preferences for lower risk and more healthy products [1012]. This acknowledgement led to a continual growth in the demand for goat meat in the United States. Thus, researchers are becoming attentive to issues of demand, supply, marketing channels, and influential factors in the goat meat market [12-15]. Yet, in contrast to many studies on beef, pork and poultry products, the investigation in the goat meat market is notably inadequate, and some crucial issues such as the market demand and consumer preferences have not been studied in the depth needed for reshaping the marketing strategies of the industry or changing the status quo of the industry. As a matter of fact, a literature review revealed only a few journal publications and the extreme paucity of analyses supported by solid data. While the call for more studies is widespread, the appreciation of effective data gathering and quantitative investigations is especially warranted.

This study is an attempt to fill in some of the gaps in quantitative analyses and estimates of the goat meat demand and the corresponding driving factors. To accomplish the task, the study uses data from a survey in eleven southern states (Alabama, Arkansas, Florida, Georgia, Mississippi, North Carolina, Oklahoma, Louisiana, South Carolina, Tennessee, and Texas) commonly known as the goat meat consumption and production region. Four econometric models were fitted to examine the multiple layers of demand, including the current demand, the potential demand, the latent demand, and the seasonal demand. As a result of the support of the robust data, this study is 
capable of providing an in-depth investigation into the promising US goat meat market.

\section{DATA}

The data used in this study were from a telephone survey conducted by the Survey Research Center of the University of Georgia. By using a random sampling procedure [16], the survey collected 11 subsamples, each with a size of 237 to 257 respondents from a state, and amounted to 2751 households.

The survey questionnaire consists of 23 simple and 25 multiple-layer questions. These questions can be grouped into six categories: 1) the status quo of goat meat consumption, including current consumption, willingness to consume more, and willingness to try if not consumed at the time of the survey; 2) consumer preferences for various goat meat cuts, different search, experience, and credence attributes; 3) cooking methods, such as soup, barbeque, roasting, meat sauce, chili, and meat loaf; 4) consumption of other meats, including beef, pork, chicken, turkey, lamb, and fish; 5) demographics, such as gender, age, ethnic affiliation, household size, and family structure; 6) socioeconomic characteristics of respondents, including education and household income.

Authors were solicitous in the selection of levels for categorical variables. Ethnic affiliation, matched the US census, is comprised of Whites, African Americans, Black non African Americans, Hispanics, Asians, and multi-racial races. Data were also collected on the origin of the ethnic groups and the length of time away from their original culture. To measure impacts of age, respondents were placed into ten age groups, with a narrower interval for the elder group given their larger likelihood of consuming goat meat products. For household income, nine levels were used with a narrower interval for the lower range of income, reflecting the early findings that the low- and middle-income households constitute the greater part of demand in the goat meat market. In view of spatial discrepancy in consumption, data from the eleven states were merged into four levels, based on the preliminary analysis. Education was initially measured at eight levels in an effort to gauge its impacts with sufficient accuracy, but the three levels as reported in Table 1 were used as suggested by the analyses. Other variables and their levels were also elucidated in Table 1. As a rule of thumb, for variables with six levels or more, trade-off between the accurate measurement of the variable and the loss of the degree of the freedom was made in favor of the degree of the freedom.

\section{METHODS}

The logistic model is used as the major analytical tool in this study. As a matured method for categorical analysis, the logistic model has been extensively used in many areas of social investigations when the dependent variable of interest is categorical [17-19]. Similar approaches in the model-building paradigm of categorical data analysis also include the Linear Probability model (LPM) and the Probit model. While the LPM is seldom used in recent years for its inherent disadvantages in estimator, variance dependence, and outbound range of response prediction, the other two approaches, especially the logistic model, have found extensive use for its handling of odds ratios via logit parameters.

A detailed elaboration of the logistic model is available in many seminal studies $[20,21]$, thereby will not be addressed here. Here a discussion of the model is limited to the level necessary for facilitating the understanding of our analyses. In general, the logistic model assumes that $y_{i j}$ is the number of occurrence of the response $j$ for $i^{\text {th }}$ observation in $N_{i}$ repetitions (if $N_{i}=1$ then $y_{i j}=0$ or 1 ) and $P_{i j}$ is defined as the probability that alternative $j$ occurs for the $i^{\text {th }}$ observation, then the multinomial probability density function is:

$$
f\left(y_{i 1} y_{i 2} \cdots y_{i J}\right)=\frac{N_{i} !}{y_{i 1} ! y_{i 2} ! \cdots y_{i J} !} P_{i 1}^{y_{i 1}} P_{i 2}^{y_{i 2}} \cdots P_{i J}^{y_{i J}}
$$

In most cases, $N_{i}=1$ for all observation units $i=1$, $2, \ldots, \mathrm{n}$, and $y_{i j}$ becomes 1 because only one of the $J$ alternatives can occur for any observation unit $i$. In such case, the log likelihood function is:

$$
L=\sum_{i=1}^{n} \sum_{j=1}^{J} y_{i j} \ln \left(p_{i j}\right)
$$

Enforcing the restriction of

$$
\sum_{j=1}^{J} P_{i j}=1,
$$

the probability of response $j$ will be:

$$
\begin{aligned}
& p_{i 1}=\frac{1}{1+\sum_{j=2}^{J} \exp \left(B_{1 j} x_{i 1}+B_{2 j} x_{i 2}+\cdots+B_{k j} x_{i k}+e_{i}\right)} \text { for } j=1 \\
& p_{i j}=\frac{\exp \left(B_{1 j} x_{i 1}+B_{2 j} x_{i 2}+\cdots+B_{k j} x_{i k}+e_{i}\right)}{1+\sum_{j=2}^{J} \exp \left(B_{1 j} x_{i 1}+B_{2 j} x_{i 2}+\cdots+B_{k j} x_{i k}+e_{i}\right)} \text { for } j \geq 2
\end{aligned}
$$

For nominal response variables, all non-reference categories are compared with a reference category and the logit of the level $j$, with the reference category $k$, is:

$$
\log \frac{p_{j}}{p_{k}}=\sum B_{j} x \quad \text { for } j=1, \cdots, J
$$

For ordinal response variables, the logistic model uses the cumulative logit function and the reference category 
Table 1. Variable definitions and summary statistics (cont.).

\begin{tabular}{|c|c|c|c|c|c|c|c|}
\hline \multirow[t]{2}{*}{ Variable } & \multirow[t]{2}{*}{ Definition \& code } & \multicolumn{6}{|c|}{ Statistics (means\%) } \\
\hline & & 0 & 1 & 2 & 3 & 4 & 5 \\
\hline Q28x1 & $\begin{array}{c}\text { Rankings of food page advertisement: } 0 \text { (important); } \\
1 \text { (neutral); } 2 \text { (not important) }\end{array}$ & 30.4 & 39.4 & 29.8 & & & \\
\hline Q29 & $\begin{array}{l}\text { Rankings of store display: } 0 \text { (important); } \\
1 \text { (neutral); } 2 \text { (not important) }\end{array}$ & 46.9 & 31.7 & 21.4 & & & \\
\hline Q30 & $\begin{array}{l}\text { Rankings of chevon price specials: } 0 \text { (important); } \\
1 \text { (neutral); } 2 \text { (not important) }\end{array}$ & 54.5 & 18.9 & 26.5 & & & \\
\hline Q30x1 & $\begin{array}{c}\text { Rankings of other meat price specials: } 0 \text { (important); } \\
1 \text { (neutral); } 2 \text { (not important) }\end{array}$ & 77.9 & 13.4 & 8.8 & & & \\
\hline Q32 & $\begin{array}{l}\text { Rankings of USDA inspection: } 0 \text { (important); } \\
1 \text { (neutral); } 2 \text { (not important) }\end{array}$ & 78.7 & 7.8 & 13.5 & & & \\
\hline Q34 & $\begin{array}{c}\text { Rankings of chevon fat content: } 0 \text { (important); } \\
1 \text { (neutral); } 2 \text { (not important) }\end{array}$ & 62.8 & 8.0 & 29.2 & & & \\
\hline Q35x1 & $\begin{array}{c}\text { Ranking of the cholesterol content: } 0 \text { (important); } \\
1 \text { (neutral); } 2 \text { (not important) }\end{array}$ & 73.7 & 7.2 & 19.1 & & & \\
\hline Q47 & Family Size: number of person in the household & & & & & & \\
\hline Q49 & $\begin{array}{l}\text { Race: } 0 \text { for White; } 1 \text { for African American; } 2 \text { for non-African } \\
\text { American; } 3 \text { for Hispanic, } 4 \text { for Asian, } 5 \text { for multi-racial }\end{array}$ & 77.2 & 13.9 & 1.4 & 2.8 & 0.5 & 2.0 \\
\hline Q54 & Age: 0 for $<34 ; 1$ for $35-54 ; 2$ for $55-64 ; 3$ for $>65$ & 22.1 & 38.7 & 16.8 & 26.2 & & \\
\hline Q55 & $\begin{array}{l}\text { Education: } 0 \text { for high school diploma or less; } 1 \text { for associate } \\
\text { degree or some college; } 2 \text { for college or higher }\end{array}$ & 34.5 & 29.2 & 34.0 & & & \\
\hline Q56 & Gender: 0 for female; 1 for male & 68.8 & 31.0 & & & & \\
\hline Q57 & $\begin{array}{l}\text { Household income: } 0 \text { (less than 19,999); } 1(20,000-34,999) \text {; } \\
2(35,000-49,999) ; 3(50,000-74,999) ; 4(75,000 \text { or more })\end{array}$ & 11.0 & 13.7 & 12.0 & 15.3 & 16.1 & \\
\hline Q58 & $\begin{array}{l}\text { Geographic location: } 0(\mathrm{TN}) \\
1 \text { (AL, AR, GA, MS, MC, OK, LA, SC) } \\
2 \text { (FL); 3(TX) }\end{array}$ & 8.9 & 73.5 & 8.6 & 9.0 & & \\
\hline
\end{tabular}

varies with the level of the response variable under consideration. The logit is defined as:

$$
\log \frac{\sum_{j=1}^{J} p_{j}}{1-\sum_{j=1}^{J} p_{j}}=\sum B_{j} x \text { for } j=1, \cdots J
$$

Parameters in a logistic model measure the logit change of the response variable for a unit change in an explanatory variable. If the explanatory variable is categorical, the parameter measures the impact of a specific level of the variable on the probability of event, given the selection of the reference level and no changes in all other variables.

The SAS software package provides a good platform for implementing the model. All data management, coding, and modeling processes have been done in the SAS environment. One thing worthy to being highlighted is that we selected reference coding for nominal variables, and used ordinal coding for ordinal variables in the model.

\section{MODEL SELECTION}

Four logit models were fitted to estimate the current demand, the potential demand, the latent demand, and the seasonal demand. Starting with a similar variable set, alternative models were screened for the best-fitting ones via multiple diagnostic statistics $[22,23]$. Given the large data set, we were able to make the selection of variables from a much broader spectrum, which partially insured the efficacy of the models retained.

The initial explanatory variable set used in modeling includes most variables in the survey; such as meat prices, rankings of the cholesterol content, rankings of fat content, other meat consumption, real income, age, education, ethnic groups, household structure, gender, and geographic locations. To identify and retain the best models, multiple statistics, including $\mathrm{R}^{2}$, AIC, LR, Pvalue, and Hosmer and Lemeshow test, weighted in the model selection $[20,24]$. A candidate model under prior consideration requires a significant LR, a lower AIC, a significant Wald statistic, and a non-significant Hosmer and Lemeshow test. Variables, lack of appropriateness 
and power, were not retained for the sake of the degree of freedom. For the variables retained, the levels of insignificance were normally merged if there are more than five originally.

\subsection{The Current Demand Model}

The model examines the existing demand and focuses on consumers who eat goat meat at the time of the survey. The dependent variable comes from the question "have you or any member of your immediate family member eaten goat meat recently?" The model starts with the consumption of goat meat substitutes (beef, pork, and chicken), demographics (household size, ethnic groups, age, and race), food safety, and socioeconomic factors (education and household real income). Fitted with a general logit function, we first tested whether the model as a whole explains the variability of the current demand, and then examined each variable and removed those of insignificance for the sake of the degree of the freedom. There were 2675 observations effective for fitting the model. The best model selected suggests an intriguing relationship between the current demand and a set of explanatory variables.

\subsection{The Potential Demand Model}

The potential demand model is to catch the potential increase in goat meat consumption due to extra consumption of the existing consumers. Differing from other meat markets, the goat meat market is featured with consumers of low per capita consumption, an average of about 4 pounds annually. A question to be raised is: whether the consumers have the willingness to purchase more? And if yes, under what conditions? The question asked in our survey is "would your family eat more goat meat if it was available in your local grocery stores?" Responses to the question suggest the existence of a large potential of demand. The model identified meets the needs of a robust model and provides some insightful marketing tips for the industry.

\subsection{The Latent Demand Model}

The latent demand model examines the potential increase in goat meat consumption due to the influx of new consumers. About $20 \%$ of consumers, not eating goat meat at the time of the survey, were willing to make purchase if available locally. The latent demand fitted would help to get a full view of the future expansion of the US goat meat market. The response variable is derived from the survey question "Do you think you will try goat meat if it is available in your area food stores?" Following the procedures in model (1) and (2), the latent demand model was identified.

\subsection{The Seasonal Demand Model}

The seasonal demand largely characterizes the status quo of the existing US goat meat market. Based on the survey data, the seasonal and occasional consumers accounted for $73 \%$ of the goat meat market consumption. To have a broad understanding of the seasonality, we intended to have a multinomial logit model which separates spring, winter, summer, winter demand as well as the social and demographic factors. However, the issue of missing values in observations impeded our efforts. As an alternative, we fitted a simple logit model with a dependent variable of two levels: seasonal or non-seasonal consumption. We identified a seasonal demand model, but found it less robust in statistics and lack of explanatory power in both theory and practice.

\section{RESULTS AND DISCUSSION}

The SAS results confirm the existence of explanatory variable sets of appropriateness and significance for each demand model. The four models fitted provide a highdimension view of consumer demand and preferences in the US goat meat market.

\subsection{Current Demand}

The results of the current demand model are reported in Table 2. Those variables retained in the model shed light on the understanding of the existing US goat meat market. First, the consumption of other meats influenced the consumption of goat meat. While chicken turns out to be a complementary diet component to goat meat consumers, pork consumption appears to reduce the likelihood of goat meat consumption or is a substitute. No significant relationships between the consumption of goat meat and other types of meat were identified.

As expected, demographics take a role in goat meat demand. There are remarkable differences in consumption between ethnic groups. Taking Whites as the reference group, the odds ratios for both non-African American Blacks and Hispanics is as high as 3.42, indicating a much higher propensity to consume. However, an unexpected result is that African Americans and Asians show a similar consumption pattern as Whites in goat meat consumption. Age is another influential demographic factor; the odds ratios of the groups (55 - 64; 65 and over) are twice as high as the odds ratio of young age group $(0-34)$. This result highlights the propensity of the elder to consume, specifically for the group aged 55 64. Reflecting the effect of gender, male consumers have a smaller odds ratio than females, suggesting men are less likely to consumer goat meat.

Socioeconomic factors are relevant, but the impacts defy the conventional wisdom with a negative relationship between household income and goat meat consump- 
Table 2. Existing demand and variables associated.

\begin{tabular}{|c|c|c|c|c|c|}
\hline Variable & Level & Estimate & Wald Statistics & P-Value & OR \\
\hline Intercept $^{* * *}$ & 1 & -1.63 & 13.99 & 0.00 & 0.20 \\
\hline Chicken consumption $^{* *}$ & 1 & 0.33 & 6.39 & 0.01 & 1.39 \\
\hline Chicken consumption & 2 & -0.42 & 1.50 & 0.22 & 0.66 \\
\hline Chicken consumption $^{*}$ & 3 & -0.96 & 3.04 & 0.08 & 0.38 \\
\hline Pork consumption & 1 & -0.36 & 7.78 & 0.00 & 0.70 \\
\hline Pork consumption ${ }^{* *}$ & 2 & -0.43 & 6.23 & 0.01 & 0.65 \\
\hline Pork consumption & 3 & -0.33 & 2.15 & 0.14 & 0.72 \\
\hline Family size & 0 & 0.05 & 2.09 & 0.14 & 1.05 \\
\hline Race & 1 & 0.24 & 2.07 & 0.14 & 1.27 \\
\hline $\operatorname{Race}^{* * *}$ & 2 & 1.23 & 9.98 & 0.00 & 3.42 \\
\hline $\operatorname{Race}^{* * *}$ & 3 & 1.23 & 9.39 & 0.00 & 3.42 \\
\hline Race & 4 & 0.34 & 0.25 & 0.61 & 1.40 \\
\hline $\operatorname{Race}^{* *}$ & 5 & 1.07 & 7.41 & 0.00 & 2.92 \\
\hline $\operatorname{Age}^{* * *}$ & 1 & 0.49 & 9.35 & 0.00 & 1.63 \\
\hline $\mathrm{Age}^{* * *}$ & 2 & 0.73 & 7.00 & 0.00 & 2.08 \\
\hline $\operatorname{Age}^{* * *}$ & 3 & 0.65 & 6.31 & 0.00 & 1.92 \\
\hline Gender $^{* * *}$ & 1 & -0.77 & 4.86 & 0.00 & 0.46 \\
\hline Income $^{*}$ & 0 & 0.38 & 3.30 & 0.06 & 1.46 \\
\hline Income & 1 & 0.13 & 0.46 & 0.49 & 1.14 \\
\hline Income & 2 & -0.20 & 0.91 & 0.33 & 0.82 \\
\hline Income & 4 & -0.18 & 0.86 & 0.35 & 0.84 \\
\hline State & 1 & 0.24 & 1.72 & 0.19 & 1.27 \\
\hline State & 2 & -0.34 & 2.48 & 0.11 & 0.71 \\
\hline State $^{* * *}$ & 3 & 0.59 & 6.36 & 0.00 & 1.80 \\
\hline
\end{tabular}

Note: ${ }^{* * *}$ significant at the 0.01 level; ${ }^{* *}$ significant at the 0.05 level; ${ }^{*}$ significant at the 0.10 level.

tion. The households with $\$ 20,000$ income or less are more likely to eat goat meat than the households with higher income. This result is likely due to the influence of the conventional belief in the inferior quality of goat meat. There is no complex spatial pattern in goat meat consumption. Most states are alike in sharing the propensity to consume goat meat except Texas and Florida. Texan tops other states in the likelihood of goat meat consumption while Florida is at the bottoms.

\subsection{Potential Demand}

The results of potential increase in per capita consumption are reported in Table 3. Starting with a similar exploratory variable set, this model ends with a number of quite different variables featuring preference variables, which are largely absent in the first model.

The consumption of other meats impacts on the consumption of goat meat and the influence is more closely related to the frequency of other meat consumption. Consumers, who purchase beef and chicken regularly, show a large odds ratio of being willing to purchase more goat meat, suggesting a positive relationship between other meat consumption and goat meat purchase.

The impacts of demographics remain, but are much weaker. The influence of age is discernible, featured by the willingness of the age group 55 - 64 to purchase more than all other age groups. Also evident is the impact of gender; males are less likely to increase their purchase than females. Nevertheless, ethnic affiliations are out of the model, implying that goat meat as a regular diet is not taken for granted even by ethnic groups.

While demographics take less weight and socioeconomic factors largely missed in influencing the potential demand, consumer preferences carry more in explaining the willingness of purchasing more goat meat. Three preference variables (price specials, safety assurance, and fat contents) were retained in the model, suggesting that lower goat meat price, better safety assurance, and lower fat content labeling are attractive to consumers who tend to consumer more goat meat. This finding signals possible attributes of a marketing strategy to expand the goat industry. 
Table 3. Potential demand and variables associated.

\begin{tabular}{|c|c|c|c|c|c|}
\hline Variable & Level & Estimate & Wald Statistics & P-Value & OR \\
\hline Intercept & 1 & 0.31 & 2.16 & 0.14 & 1.36 \\
\hline Price special $^{* * *}$ & 0 & -1.04 & 7.95 & 0.00 & 0.35 \\
\hline Price special $^{* * *}$ & 1 & -1.58 & 9.95 & 0.00 & 0.21 \\
\hline USDA inspection & 0 & 0.42 & 1.46 & 0.22 & 1.52 \\
\hline USDA Inspection ${ }^{* *}$ & 1 & -0.48 & 3.83 & 0.05 & 0.62 \\
\hline Fat content ${ }^{*}$ & 0 & -0.49 & 3.22 & 0.07 & 0.61 \\
\hline Fat content & 1 & -0.26 & 2.30 & 0.12 & 0.77 \\
\hline Beef consumption ${ }^{* *}$ & 1 & -0.28 & 4.95 & 0.02 & 0.76 \\
\hline Beef consumption $^{*}$ & 2 & -0.42 & 2.79 & 0.09 & 0.66 \\
\hline Beef consumption & 3 & 0.08 & 0.04 & 0.82 & 1.08 \\
\hline Chicken consumption & 1 & -0.23 & 2.41 & 0.12 & 0.79 \\
\hline Chicken consumption & 2 & -0.44 & 1.46 & 0.22 & 0.64 \\
\hline Chicken consumption ${ }^{* *}$ & 3 & -1.48 & 4.80 & 0.02 & 0.23 \\
\hline Age & 1 & 0.14 & 0.93 & 0.33 & 1.15 \\
\hline $\mathrm{Age}^{*}$ & 2 & 0.33 & 3.28 & 0.07 & 1.39 \\
\hline Age & 3 & 0.26 & 2.13 & 0.14 & 1.30 \\
\hline Gender $^{* * *}$ & 1 & -0.91 & 5.53 & 0.00 & 0.40 \\
\hline State & 1 & 0.19 & 1.01 & 0.31 & 1.21 \\
\hline State $^{* *}$ & 2 & 0.46 & 6.11 & 0.01 & 1.58 \\
\hline State & 3 & -0.05 & 0.07 & 0.78 & 0.95 \\
\hline
\end{tabular}

Note: ${ }^{* * *}$ significant at the 0.01 level; ${ }^{* *}$ significant at the 0.05 level; ${ }^{*}$ significant at the 0.10 level.

\subsection{Latent Demand}

The results of potential increase in goat meat demand from the influx of new consumers who have not previously eaten goat meat are reported in Table 4 . The results show sizeable potential entrants with distinguishable demographic and socioeconomic characteristics.

Again, demographics are linked with willingness of trying goat meat. With a four-fold larger odds ratio than Whites, African Americans and multiple racial households are more likely to be the new entrant. Age factor again shows its influence, evidenced by the fact that the elder is more likely to try goat meat than the young (0 34 ), this is especially true for the group aged 55 or over. The impact of gender is insignificant, though it points toward more flexibility of females than males in trying goat meat.

Both socioeconomic factors, education and household income, demonstrate a U-shaped impact on consumers' willingness to enter the goat meat market. Taking the educational level of high school or less as the reference, consumers with an associate degree or some college education are less willing to try goat meat, but those with full college or higher education are more likely to trying. Likewise, the middle income households are more hesitated to try goat meat than their counterparts at the lower and higher spectrum of incomes.

Once again, consumer preferences hold the edge in influential factors related to latent demand. Preferences for cooking instruction, cooking methods (broiling and barbeque), store display, price specials, and safety assurance were retained in the model. The odds ratios of those consumer preferences demonstrate that consumer' preferences for cooking guidance, price specials, and food safety may stimulate an influx of new consumers into the goat meat market.

\subsection{Seasonal Demand}

The results of the seasonal demand model are reported in Table 5. Few variables have been retained and less insightful suggestions are offered in this model.

Limited information conveyed in this model suggests that chicken consumers tend to have seasonal consumption of goat meat and eating other meat seems to have no significant impact on goat meat consumption. Male consumers and those sensitive to price specials are more likely to change their consumption in different seasons. In addition, consumers favoring less cholesterol comprise the large portion of seasonal purchasers of goat meat.

Beyond the results observed above, it is an insurmountable challenge to further clarify the profile of regular 
Table 4. Latent demand from new consumers and variables associated.

\begin{tabular}{|c|c|c|c|c|c|}
\hline Variable & Level & Estimate & Wald Statistics & P-Value & OR \\
\hline Intercept $^{* *}$ & 1 & 1.52 & 5.22 & 0.02 & 4.57 \\
\hline Cooking instruction $^{* * *}$ & 0 & -1.89 & 7.89 & 0.00 & 0.15 \\
\hline Cooking instruction & 1 & -0.45 & 1.57 & 0.20 & 0.64 \\
\hline Broiling goat meat $^{* *}$ & 0 & 1.14 & 4.16 & 0.04 & 3.13 \\
\hline Broiling goat meat & 1 & -0.28 & 0.37 & 0.54 & 0.76 \\
\hline Barbeque & 0 & -0.29 & 0.52 & 0.46 & 0.75 \\
\hline Barbeque ${ }^{* * *}$ & 1 & -1.62 & 7.31 & 0.00 & 0.20 \\
\hline Store display & 0 & 0.10 & 0.03 & 0.85 & 1.11 \\
\hline Store display $^{* *}$ & 1 & -0.87 & 6.08 & 0.01 & 0.42 \\
\hline Price special $^{* *}$ & 0 & -2.45 & 5.76 & 0.01 & 0.09 \\
\hline Price special & 1 & -0.64 & 2.09 & 0.14 & 0.53 \\
\hline USDA inspection ${ }^{* * *}$ & 0 & 3.00 & 6.60 & 0.01 & 20.09 \\
\hline USDA inspection $^{* *}$ & 1 & -1.57 & 4.69 & 0.03 & 0.21 \\
\hline $\operatorname{Race}^{* * *}$ & 1 & 1.42 & 8.00 & 0.00 & 4.14 \\
\hline Race & 2 & 0.88 & 0.91 & 0.33 & 2.41 \\
\hline Race & 3 & -0.15 & 0.08 & 0.76 & 0.86 \\
\hline Race & 4 & -1.51 & 0.72 & 0.39 & 0.22 \\
\hline Race $^{*}$ & 5 & 1.57 & 2.85 & 0.09 & 4.81 \\
\hline Age & 1 & 0.45 & 1.11 & 0.29 & 1.57 \\
\hline $\operatorname{Age}^{* *}$ & 2 & 1.16 & 5.38 & 0.02 & 3.19 \\
\hline $\mathrm{Age}^{*}$ & 3 & 0.88 & 3.16 & 0.07 & 2.41 \\
\hline Gender & 1 & -0.47 & 2.21 & 0.13 & 0.63 \\
\hline Education $^{*}$ & 1 & -0.64 & 2.99 & 0.08 & 0.53 \\
\hline Education & 2 & 0.61 & 2.47 & 0.11 & 1.84 \\
\hline Income & 1 & -0.52 & 0.94 & 0.33 & 0.59 \\
\hline Income $^{* *}$ & 2 & -1.22 & 4.06 & 0.04 & 0.30 \\
\hline Income & 3 & 0.25 & 0.23 & 0.62 & 1.28 \\
\hline Income & 4 & 0.03 & 0.00 & 0.95 & 1.03 \\
\hline State & 1 & 0.26 & 0.28 & 0.59 & 1.30 \\
\hline State & 2 & 0.28 & 0.21 & 0.64 & 1.32 \\
\hline State & 3 & -0.65 & 2.28 & 0.13 & 0.52 \\
\hline
\end{tabular}

Note: ${ }^{* * *}$ significant at the 0.01 level; ${ }^{* *}$ significant at the 0.05 level; ${ }^{*}$ significant at the 0.10 level.

goat meat consumers against those of sporadic and seasonal consumers even with the support of a large survey data set. The ill-fitted model reflects the empirical reality of the fuzzy division across regular and seasonal consumers in the goat meat market. No practical ways are readily available in the fitted model for transferring the seasonal demand to a year round demand in the US goat meat market. Possibly, there is no such one-size-fits-all way of reshaping the seasonality in goat meat consumption. More investigations are obviously needed in this direction.

\section{CONCLUSIONS}

Demand for goat meat and its potential growth are evidenced in this study. A promising US goat meat market mirrors itself in four layers of demand model: current demand, potential demand increase of current consumers, latent demand of new consumers, and seasonal demand.

The US goat meat market isn't trivial because seventeen percent of consumers currently purchase goat meat. The lower income, the elder, and the ethnic groups comprise the current goat meat niche market. The niche is expected to grow with more demographically homogenous immigrants from developing countries and the coming retirement of the "baby boom" generation.

The incremental demand of current consumers and latent demand of consumers who never eat goat meat are likely to stimulate the expansion of the US goat meat market. Therefore, the growth potential is not driven just by the size of ethnic groups or the elder, but also by consumer preferences for healthy and safer attributes of goat meat. The provision of goat meat products with the attributes may define the future of the US goat meat 
Table 5. Seasonal demand and variables associated.

\begin{tabular}{cccccc}
\hline Variable & Level & Estimate & Wald Statistics & P-value & OR \\
\hline Intercept & 1 & 1.33 & 2.50 & 0.11 & 3.78 \\
Price special $^{*}$ & 1 & 0.59 & 3.22 & 0.07 & 1.80 \\
Price special $^{* *}$ & 2 & -1.25 & 4.09 & 0.04 & 0.29 \\
Cholesterol level $^{* *}$ & 1 & --0.61 & 5.18 & 0.02 & 0.54 \\
Cholesterol level $^{* *}$ & 2 & -0.22 & 0.23 & 0.62 & 0.80 \\
Chicken consumption $^{* *}$ & 1 & -1.56 & 4.67 & 0.03 & 0.21 \\
Chicken consumption $^{*}$ & 2 & -1.35 & 3.38 & 0.06 & 0.26 \\
Chicken consumption $^{* *}$ & 4 & -3.39 & 5.69 & 0.01 & 0.03 \\
Lamb consumption $^{\text {Lamb consumption }}$ & 1 & -0.93 & 0.56 & 0.45 & 0.39 \\
Lamb consumption $^{* *}$ & 2 & -0.41 & 0.56 & 0.45 & 0.66 \\
Seafood consumption $^{*}$ & 4 & 0.34 & 2.31 & 0.12 & 1.40 \\
Seafood consumption $^{* *}$ & 1 & -0.13 & 0.17 & 0.67 & 0.88 \\
Seafood consumption $^{\text {Gender }}{ }^{* * *}$ & 2 & -0.67 & 4.97 & 0.02 & 0.51 \\
\hline
\end{tabular}

Note: ${ }^{* * *}$ significant at the 0.01 level; ${ }^{* *}$ significant at the 0.05 level; ${ }^{*}$ significant at the 0.10 level.

industry.

The seasonal demand is likely to keep its dominance in the US goat meat market for some time into the future. So far as the results of our study and findings of others, it is not readily available to have one-size-fits-all identifying the shift of the US goat meat market from a market of seasonal demand dominance into a market with a stable year round demand.

\section{REFERENCES}

[1] USDA/Economic Research Service (2002) Changing consumer demands create opportunities for US food system. Food Review, 25, 19-22.

[2] Menkhaus, D.J., Colin, D.P.M., Whipple, G.D. and Field, R.A. (1993) The effects of perceived product attributes on the perception of beef. Agribusiness, 9, 57-63. http://dx.doi.org/10.1002/1520-6297(199301)9:1<57::AI D-AGR2720090106>3.0.CO;2-8

[3] Grunert, K.G. (2005) Food quality and safety: Consumer perception and demand. European Review of Agricultural Economics, 32, 369-391. http://dx.doi.org/10.1093/eurrag/jbi011

[4] Piggott, N.E. and Marsh, T.L. (2004) Does food safety information impact US meat demand? American Journal of Agricultural Economics, 86, 154-174. http://dx.doi.org/10.1111/j.0092-5853.2004.00569.x

[5] Ellen, J.V.L., Caputo, V., Rodolfo, M., Jean-Francois, M. and Ricke, S.C. (2011) Consumers' willingness to pay for organic chicken breast: Evidence from choice experiment. Food Quality and Preference, 22, 603-613. http://dx.doi.org/10.1016/j.foodqual.2011.02.003

[6] Gao, X.M. and Spreen, T. (1994) A micro-econometric analysis of the United States meat demand. Canadian Journal of Agricultural Economics, 42, 397-412. http://dx.doi.org/10.1111/j.1744-7976.1994.tb00033.x

[7] Loureiro, M.L. and Umberger, W.J. (2007) Estimating consumer willingness to pay for country-of-origin labeling. Journal of Agricultural and Resource Economics, 28, 287-301.

[8] Moschini, G. and Meilke, K.D. (1989) Modeling the pattern of structural change in US meat demand. American Journal of Agricultural Economics, 71, 253-261. http://dx.doi.org/10.2307/1241582

[9] Resurreccion, A.V.A. (2003) Sensory aspects of consumer choices for meat and meat products. Meat Science, 66, 11-20. http://dx.doi.org/10.1016/S0309-1740(03)00021-4

[10] Anaeto, M., Adeyeye, J.A., Chioma, G.O., Olarinmoye, A.O. and Tayo, G.O. (2010) Goat products: Meeting the challenges of human health and nutrition. Agriculture \& Biology Journal of North America, 1, 1231-1236. http://dx.doi.org/10.5251/abjna.2010.1.6.1231.1236

[11] Babiker, S.A., Khider, E.L. and Shafie, S.A. (1990) Chemical composition and quality attributes of goat meat and lamb. Meat Science, 28, 273-277.

http://dx.doi.org/10.1016/0309-1740(90)90041-4

[12] Rhee, K.S., Myers, C.E. and Waldron, D.F. (2003) Consumer sensory evaluation of plain and seasoned goat meat and beef products. Meat Science, 65, 785-789. http://dx.doi.org/10.1016/S0309-1740(02)00283-8

[13] Dubeuf, J.P., Morand-Fehr, P. and Rubino, R. (2004) Situation, changes and future of goat industry around the world. Small Ruminant Research, 51, 165-173. http://dx.doi.org/10.1016/j.smallrumres.2003.08.007

[14] Prinkerton, F.E., Escobar, N., Harwell, L. and Drinkwater, W. (1994) Marketing channels for meat goats in southern United States. Journal of Animal Science, 72, 49. 
[15] Zachery, N. and Nelson, M. (1992) Consumers' knowledge and use of goat products: An Atlanta case study. PAWC proceedings: Challenges in Agricultural and Rural Development, Tuskegee University, Tuskegee, 157-164.

[16] Cochran, W.G. (1963) Sampling techniques, vol. 2. Wiley, New York.

[17] Agresti, A. (2002) Categorical data analysis. Wiley, New York. http://dx.doi.org/10.1002/0471249688

[18] Greene, W.H. (2000) Models with discrete dependent variables. In: Greene, W.H., Ed., Econometric Analysis, Prentice-Hall, Upper Saddle River, 499-521.

[19] Estrella, A. (1998) A new measure of fit for equations with dichotomous dependent variables. Journal of Business Economics and Statistics, 16, 198-205.

[20] Hosmer Jr., D.W and Lemeshow, S. (2000) Applied logis- tic regression. 2nd Edition, John Wiley \& Sons, Inc., New York. http://dx.doi.org/10.1002/0471722146

[21] Stokes, M.E., Davis, C.S. and Koch, G.G. (2000) Categorical data analysis using the SAS system. SAS Institute Inc., Cary.

[22] Hocking, R.R. (1976) The analysis and selection of variables in linear regression. Biometrics, 32, 1-49. http://dx.doi.org/10.2307/2529336

[23] Judge, G.G., Griffiths, W.E., Hill, R.C. and Lee, T.C. (1980) The theory and practice of econometrics. John Wiley \& Sons, New York.

[24] Wallace, T.D. (1977) Pretest estimation in regression: A survey. American Journal of Agricultural Economics, 59, 431-443. http://dx.doi.org/10.2307/1239645 